\title{
An in vitro system of autologous lymphocytes culture that allows the study of homeostatic proliferation mechanisms in human naive CD4 T-cells
}

\author{
Isaac Rosado-Sánchez ${ }^{1}$ - Amaia González-Magaña ${ }^{1}$ - María M Pozo-Balado ${ }^{1}$ Inés Herrero-Fernández ${ }^{1}$ • \\ María J Polaino ${ }^{1}$ - María M Rodríguez-Méndez ${ }^{1}$ - María Francisca González-Escribano ${ }^{2} \cdot$ Manuel Leal $^{1}$. \\ Yolanda M Pacheco ${ }^{1}$
}

Received: 5 October 2017 / Revised: 8 November 2017 / Accepted: 20 November 2017

(c) United States \& Canadian Academy of Pathology 2018

\begin{abstract}
The size of peripheral T-cell pool is kept constant throughout life. However, a decline in lymphocyte numbers is a feature of several human disorders, in which fast and slow homeostatic proliferation play a crucial role. Several in vitro and in vivo models have been developed to study such processes. Nevertheless, self- and commensal- antigens, well-known triggers of homeostatic proliferation, have not been examined in these models. We have designed an in vitro culture of human T-cells exposed to rIL7 and autologous antigen-presenting cells (aAPC) that allows the simultaneous characterization of the different types of homeostatic proliferation. Using our model, we first confirmed that both rIL7 and aAPC are survival signals ultimately leading to homeostatic proliferation. In addition, we explored the modulation of different anti-apoptotic, proliferative, activation and homing markers during fast and slow homeostatic proliferation. Finally, different subsets of Treg were generated during homeostatic proliferation in our model. In summary, our in vitro system is able to simultaneously reproduce both types of homeostatic proliferation of human naive CD4 T-cells, and allows the characterization of these processes. Our in vitro system is a useful tool to explore specific features of human homeostatic proliferation in different human lymphopenia-related disorders and could be used as a cell therapy approach.
\end{abstract}

The size and composition of human peripheral T-cell pool is homeostatically kept constant throughout life $[1,2]$. However, immune insults as several viral infections, autoimmune disorders, chemotherapy against cancer and different drugs can lead to lymphopenia. After such attacks, the CD4 T-cell pool is not uniformly restored, and the restoration of the naive compartment is usually delayed [3, 4]. However, the CD4 naive T-cell compartment is critical for immune competence [5].

Isaac Rosado-Sánchez

isaac_rosado@hotmail.com

$\checkmark$ Yolanda M Pacheco

ypacheco-ibis@us.es

1 Laboratory of Immunovirology, Institute of Biomedicine of Seville, IBiS, Virgen del Rocío University Hospital/CSIC/ University, Seville 41013, Spain

2 Immunology Service, Institute of Biomedicine of Seville, IBiS, Virgen del Rocío University Hospital/CSIC/University, Seville 41013, Spain
Several mechanisms are involved in the reconstitution of the naive T-cell pool. The thymus is a lymphoid organ that supports the maturation of hematopoietic precursors leading to generation of new T-cells and ensuring the preservation of TCR variability [6]. Homeostatic proliferation involves a peripheral clonal expansion of $\mathrm{T}$-cells in response to homeostatic stimuli like self- or commensal-antigens and cytokines [7]. Indeed, it is known that different types of homeostatic proliferation exist [8, 9]. Fast homeostatic proliferation is defined by a rapid cellular division of naive T-cells mediated by the low avidity TCR-contact (antigendriven proliferation) generating memory T-cells $[7,8]$. Slow homeostatic proliferation is defined by a slower cellular division of naive T-cells that does not result in a change of phenotype and is driven by homeostatic cytokines like IL7 [8]. Nevertheless, while both thymopoiesis and homeostatic proliferation contribute to reconstitution of T-cell pool, homeostatic proliferation has a crucial role in early stages of immune reconstitution $[3,4,10]$. For this reason, understanding homeostatic proliferation mechanisms in human lymphopenia-related disorders is of pivotal importance. 

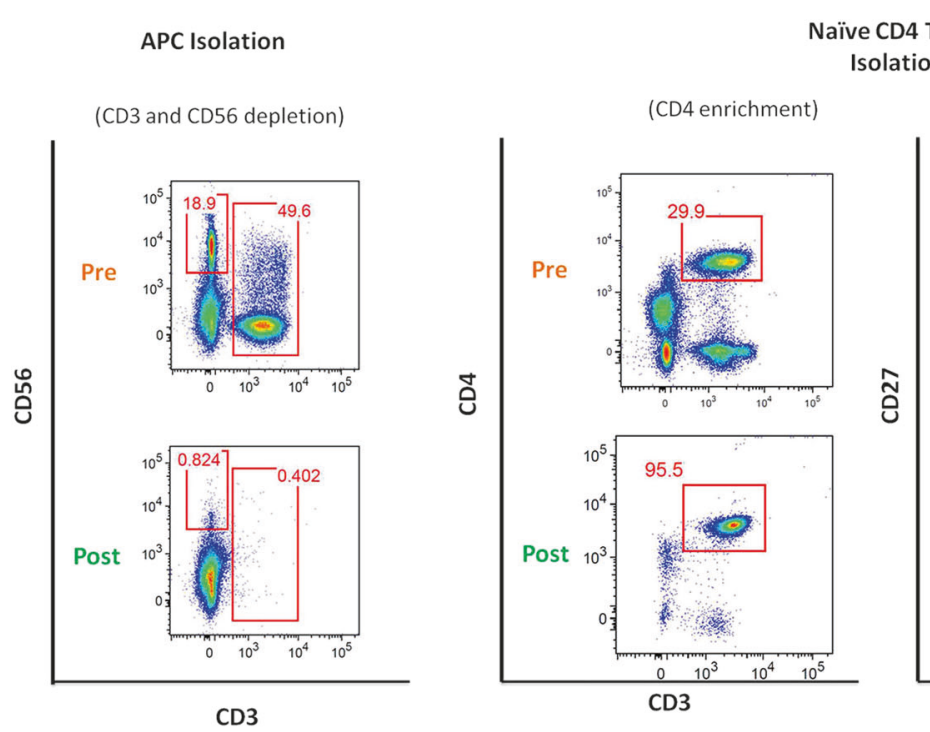

aïve CD4 T-cell

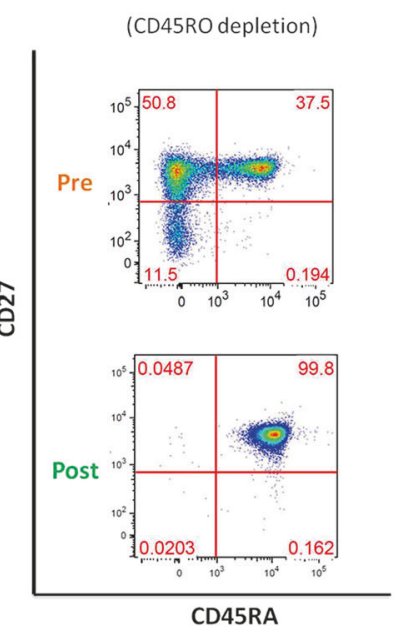

CD25 depletion

(naïve CD4 T-cell fraction)

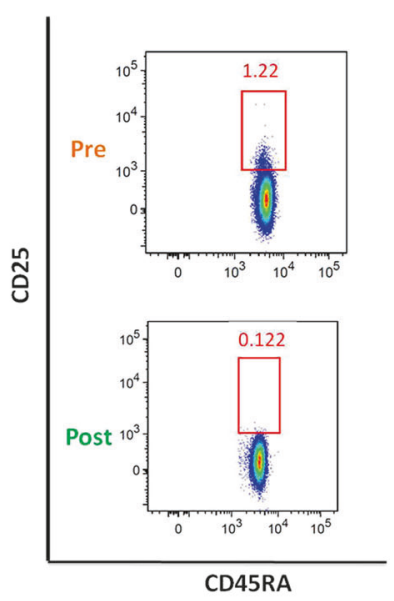

Fig. 1 Schematic representation of purity controls for isolation of cellular subsets

In order to study such processes, several in vivo models using different species of animals and chimeras are available, and several in vitro systems have been developed using antigen-presenting cells or anti-CD3/CD28 stimulation. However, self- and commensal antigens, well-known triggers of homeostatic proliferation [7], show large variability among different subjects and scenarios and natural variation has not been adequately considered in previous studies. Thus, our aim was to generate an in vitro model based on culture of human T-cells exposed to homeostatic stimuli, recombinant IL7 (rIL7) and autologous antigen-presenting cells (aAPC), allowing the simultaneous characterization of both types of homeostatic proliferation.

\section{Methods}

\section{Samples and culture design}

Buffy coat from HIV-1 and hepatitis C virus (HCV)-seronegative blood bank donors were obtained from the Centro Regional de Transfusión Sanguínea de Sevilla-Huelva y Banco de Tejidos (Seville, Spain). Using these samples, we developed an in vitro approximation based on a cellular culture in order to study homeostatic proliferation of human naive CD4 T-cells in response to different homeostatic stimuli: recombinant interleukin 7 (rIL7) and autologous antigen-presenting cells (aAPC). All experimental procedures with human blood were approved by local Ethical Committee for human research and were done according to the European Union guidelines and the Declaration of Helsinki.

\section{Cellular subsets isolation}

Briefly, peripheral blood mononuclear cells (PBMCs) were firstly obtained from buffy coats using a ficoll gradient centrifugation ( $2500 \mathrm{rpm}, 30 \mathrm{~min}$ ), and then were washed and placed in cold supplemented medium (RPMI 1640 supplemented with $10 \%$ fetal bovine serum, $1.7 \mathrm{mM}$ glutamine, $100 \mu \mathrm{l} / \mathrm{ml}$ streptomicine, and $100 \mathrm{U} / \mathrm{ml}$ peniciline). Magnetic negative isolation (StemCell, Vancouver, Canada) was used according to manufacturer's instructions to isolate cellular fractions from previously obtained PBMCs. Specifically, aAPC were obtained after depleting T-cells $\left(\mathrm{CD}^{+}\right)$and $\mathrm{NK}$ cells $\left(\mathrm{CD}^{+} 6^{+}\right.$) (human $\mathrm{CD} 3$ and CD56 positive selection kits), whereas naive CD4 T-cells were obtained after an enrichment of CD4 T-cells and a subsequent depletion of $\mathrm{CD}_{4} 5 \mathrm{RO}^{+}$cells (human NAIVE CD4 ${ }^{+}$T-cell enrichment kit). Treg-depleted fraction was obtained by depletion of $\mathrm{CD} 25^{+}$cells (human CD25 positive selection kit) in the naive T-cell fraction. A purity control was always performed after each isolation procedure by flow cytometry and only cellular fractions with a purity $\geq 95 \%$ were used in experiments. A representative example is shown in Fig. 1. The subset distribution of the APC fraction was variable among different donors (36-61\% monocytes; 11-39\% B cells; 2-13\% mDCs; $0.5-14 \%$ pDCs; min and max values).

\section{CFSE staining}

Isolated naive CD4 T-cells were stained with carboxyfluorescein succinimidyl ester (CFSE) (Sigma-Aldrich, Missouri, USA) to determine lymphocyte proliferation. Briefly, up to $1 \times 10^{7}$ cells $/ \mathrm{ml}$ of naive CD4 T-cells 

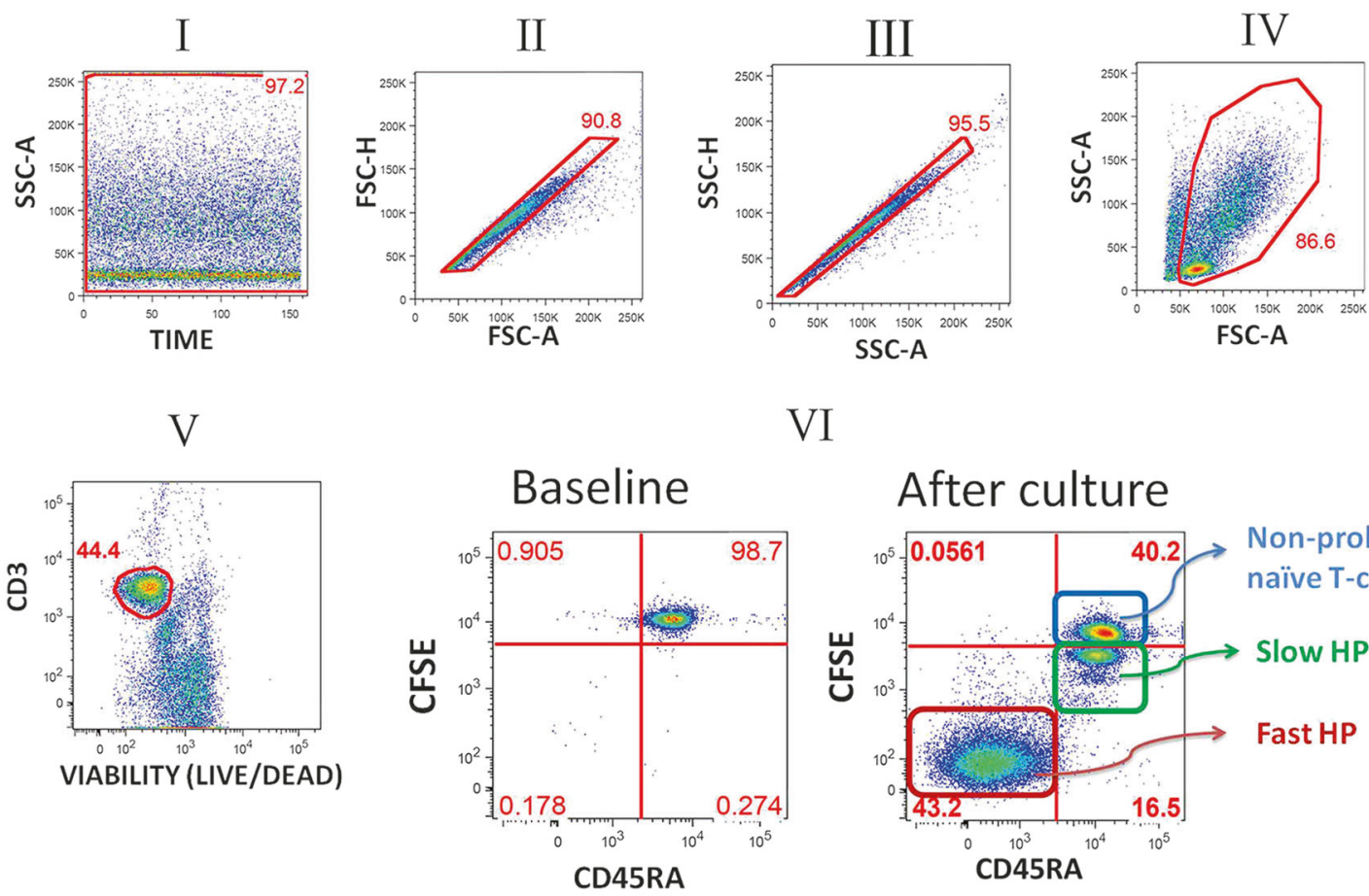

VI


\section{Non-proliferating}

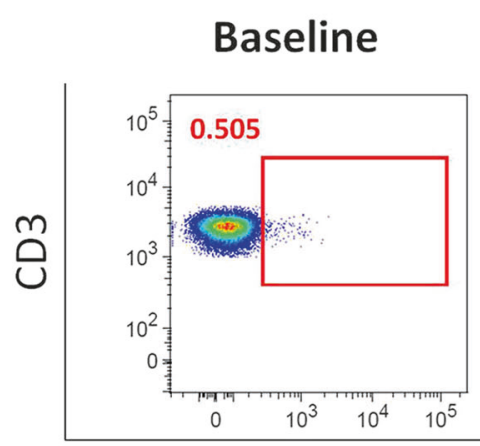

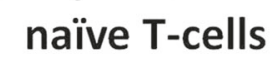

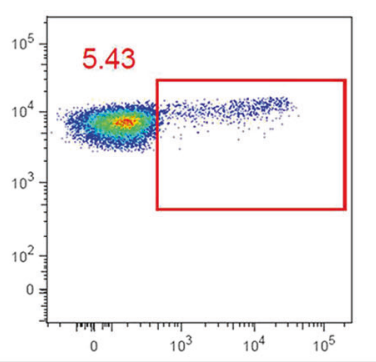

Slow HP

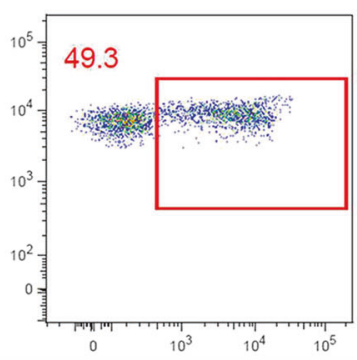

Fast HP

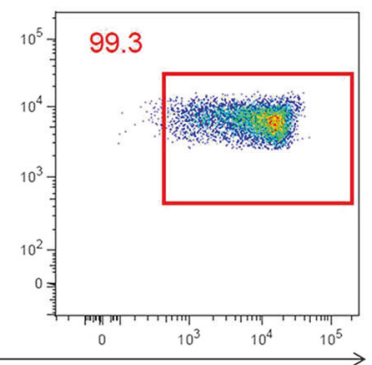

Ki67

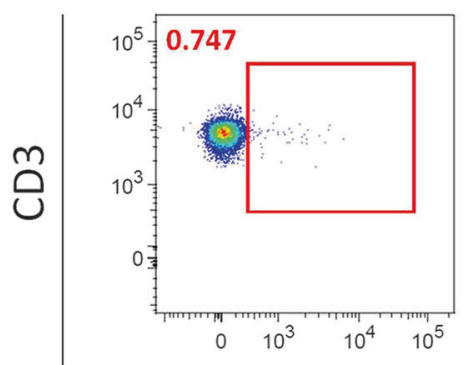

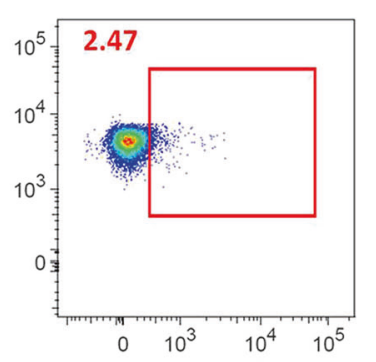
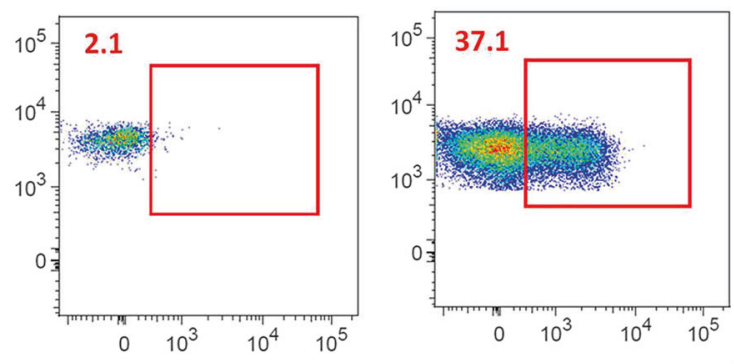

HLA-DR

Fig. 2 Schematic diagram of the gating strategy and two examples of the quantification of the expression of different T-cell markers (Ki67 and HLA-DR)

were stained in PBS (Phosphate-buffered saline) with an excess of CFSE $(2.5 \mu \mathrm{M})$ during $8 \mathrm{~min}$ at $37^{\circ} \mathrm{C}$. Finally, cells were washed and placed in cold supplemented medium.

\section{Autologous antigen-presenting cells (aAPC) irradiation}

To avoid the response of antigen-presenting cells (APC) to homeostatic stimuli and their potential interference on 
a) naïve CD4 T-cells + aAPCs

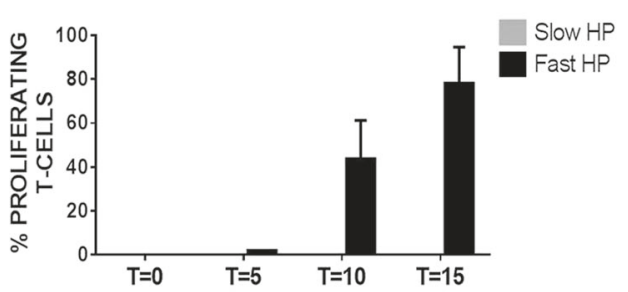

b) naïve CD4 T-cells + rIL7

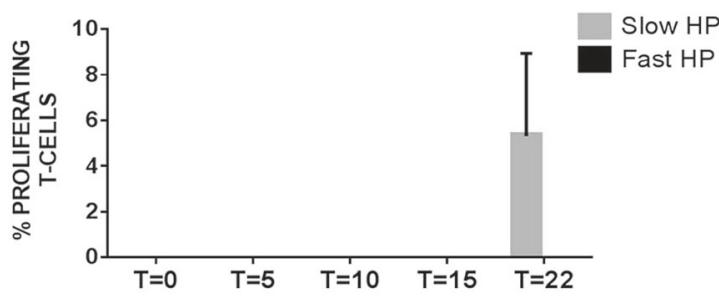

c) naïve CD4 T-cells + aAPCs + rIL7

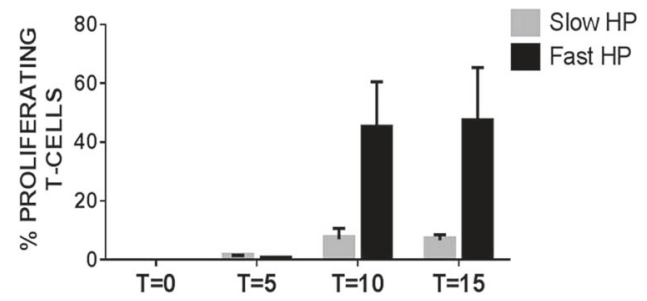

Fig. 3 Effect of different homeostatic stimuli on proliferation of human naive CD4 T-cells and representative plots. a naive CD4 T-cells stimulated with aAPC (1/1 ratio aAPC/Naive). Cell viability was $>70$ and $>60 \%$ at 10th and 15th day of culture, respectively; $\mathbf{b}$ naive CD4 T-cells stimulated with rIL7 $(10 \mathrm{ng} / \mathrm{ml})$. Cell viability was $>90 \%$ through all days of culture; $\mathbf{c}$ naive CD4 T-cells stimulated with aAPC (1/1 ratio aAPC/Naive) and rIL7 (10 ng/ml). Cell viability was $>80$ and $>70 \%$ at 10 th and 15th day of culture, respectively. Plots (right panels) show a representative experiment among each condition that were ended at

T-cell proliferation, autologous APC were irradiated in a $\gamma$ irradiator (IBL437C, Cis bioInternational, France) at dosis of $25 \mathrm{~Gy}(25 \mathrm{~J} / \mathrm{kg})$. Several aliquots of irradiated aAPC were frozen in order to re-stimulate culture with aAPC each 5 days of cell culture. The aAPC aliquots were frozen in fetal bovine serum with $10 \% \mathrm{v} / \mathrm{v}$ of Dimethil Sulfoxide (DMSO).

\section{Culture conditions}

In all culture conditions, 200,000 naive CD4 T-cells per well were seeded in a 96-well plate (Thermo Fissher, Massachusetts, USA) with supplemented medium at a concentration of $1 \times 10^{6} \mathrm{cells} / \mathrm{ml}$. Then, the homeostatic stimuli (autologous APC and rIL7) were provided.
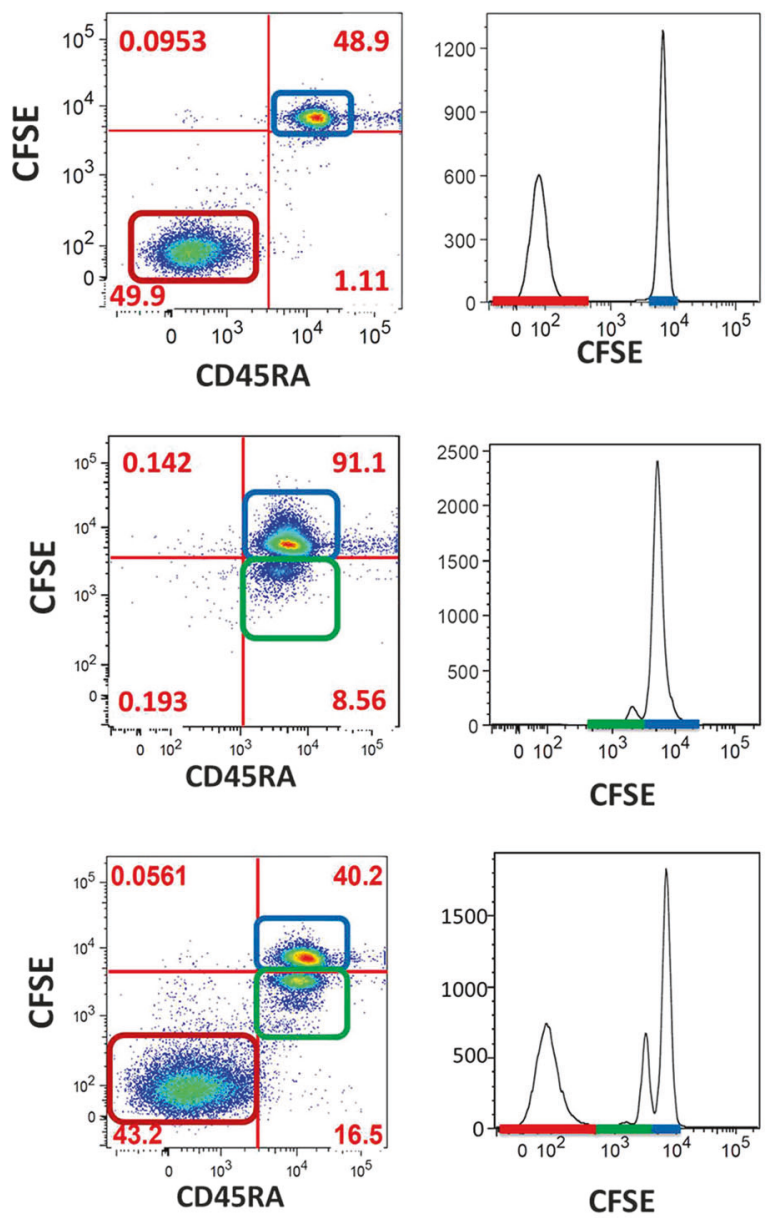

10th, 22th, and 10th days of culture, respectively. In addition, a condition without stimuli was also carried out (data not shown), but no cell proliferation and reduced cell viability was observed. Data in bar charts are representative of at least three independent experiments (a different donor each experiment) and represent median value and standard deviation (SD). Fast homeostatic proliferation, slow homeostatic proliferation and non-proliferating T-cells are highlighted in right panels using red, green and blue boxes and lines, respectively

Specifically, 200,000 irradiated aAPC were added, stablishing a 1:1 ratio of aAPC/Naive CD4 T-cells (aAPC/Naive ratio), although other aAPC/Naive ratios were also tested varying the amount of aAPC fraction. On the other hand, rIL7 was used at a concentration between 1 and $10 \mathrm{ng} / \mathrm{ml}$, whereas the condition without rIL7 only included the rIL7carrier solution (PBS with $2 \%$ fetal bovine serum and $1 \mathrm{mM}$ EDTA). All these components were placed at the 96-well plate and an aliquot was therefore used to perform the basal analyses (day 0 ). The culture was then placed in a culture incubator at $37^{\circ} \mathrm{C}$ and $5 \% \mathrm{CO}_{2}$ atmosphere. After each 5 days of culture, the half of medium volume was refreshed with new supplemented medium and thawed irradiated aAPC and rIL7. Thus, cells were recovered from independent wells at day 5, 10 and 15 of culture, and cellular 


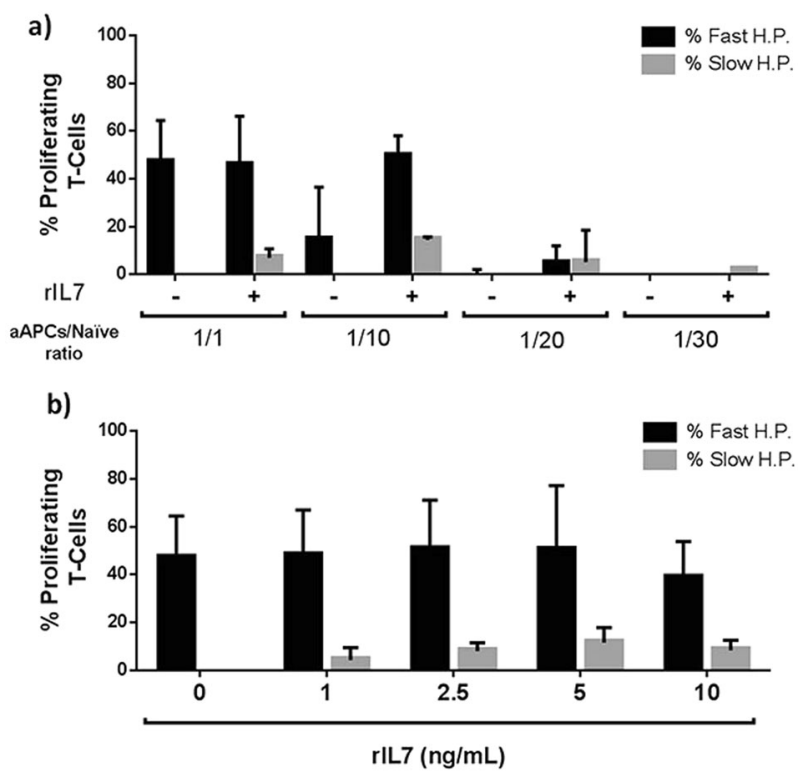

Fig. 4 Effect of different aAPC/Naive ratios and rIL7 concentrations on both types of homeostatic proliferation. a effect of different aAPC/ Naive ratios on homeostatic proliferation process (with $2.5 \mathrm{ng} / \mathrm{ml}$ rIL7); b effect of different concentrations of rIL7 $(0-10 \mathrm{ng} / \mathrm{ml})$ on homeostatic proliferation process (with $1 / 1$ ratio aAPC/Naive). Data were obtained at 10th day of culture of at least 3 independent experiments (a different donor each experiment) and are represented as median value and standard deviation $(\mathrm{SD})$

viability was determined using Trypan Blue (SigmaAldrich, Missouri, USA). To determine the intracellular production of TGF- $\beta, 10 \mathrm{ng} / \mathrm{ml}$ of brefeldin A (Biolegend, USA) was added $12 \mathrm{~h}$ before ending the cell culture.

\section{Immunophenotyping}

Immunophenotyping of culture conditions was carried out using multiparametric flow cytometry. Briefly, cells were incubated at $4{ }^{\circ} \mathrm{C}$ with surface antibodies for $20 \mathrm{~min}$, followed by fixation and permeabilization according to the manufacturer's instructions (Foxp3/Transcription Factor Staining Buffer, Ebioscience), and subsequently incubated with intracellular antibodies for $30 \mathrm{~min}$. Viable cells were identified using LIVE/DEAD fixable Aqua Blue Dead Cell Stain (Life Technologies, USA). Extracellular and intracellular antibodies were: anti-CD3 (Clone: SK7; Fluorophore: APC-H7), anti-CD4 (Clone: L200; Fluorophore: Brilliant Violet 786), anti-CD56 (Clone: NCAM16.2; Fluorophore: Brilliant Violet 421), anti-CD197/CCR7 (Clone: 3D12; Fluorophore: Brilliant Violet 786), antiTGF- $\beta$ (Clone: TW4-9E7; Fluorophore: PE), anti-CD25 (Clone: 2A3; Fluorophore: Brilliant Violet 605), anti-HLADR (Clone: G46-6; Fluorophore: PE-Cy7), antiFoxP3 (Clone: 259D/C7; Fluorophore: PE-CF594), antiCD45RA (Clone: HI100; Fluorophore: Brilliant Violet 650), anti-Ki67 (Clone: B56; Fluorophore: AlexaFluor700),
anti-BCL2 (Clone: Bcl-2/100; Fluorophore: V450), anti- $\beta 7$ integrin (Clone: FIB504; Fluorophore: APC), anti-CD19 (Clone: HIB19; Fluorophore: FITC), anti-CD14 (Clone: МфР9; Fluorophore: BV711), anti-CD123 (clone: 7G3; Fluorophore: PerCP-Cy5.5), anti-CD11c (Clone: B-ly6, Fluorophore: PE-CF594) (BD Biosciences, USA), antiCD27 (Clone: O323; Fluorophore: AlexaFluor700) (eBiocience, USA), anti-HLA ${ }^{-}$DR (Clone: L243, Fluorophore $=$ BV570) $($ Biolegend, USA). Fluorescence Minus One (FMO) and isotype controls were included when necessary. A schematic diagram of the gating strategy used is shown in Fig. 2. CD4 T-cell subsets were defined as follows: naive $\left(\mathrm{T}_{\mathrm{N}} ; \mathrm{CD} 45 \mathrm{RA}^{+} \mathrm{CD} 27^{+}\right)$, central memory


$\left(\mathrm{T}_{\mathrm{TM}}\right.$; $\mathrm{CD} 45 \mathrm{RA}^{-} \mathrm{CD} 27^{+} \mathrm{CCR} 7^{-}$), effector memory ( $\mathrm{T}_{\mathrm{EM}}$; $\mathrm{CD} 4 \mathrm{RA}^{-} \mathrm{CD}^{-} 7^{-}$) and terminally differentiated ( $\mathrm{T}_{\mathrm{EMRA}}$; $\mathrm{CD}^{2} \mathrm{RA}^{+} \mathrm{CD}^{2} 7^{-}$). Different APC subsets were defined as $\mathrm{B}$ cells $\left(\mathrm{CD}^{-} \mathrm{CD} 19^{+}\right)$, monocytes $\left(\mathrm{HLA}-\mathrm{DR}{ }^{+} \mathrm{CD} 14^{+}\right)$, mDCs (HLA-DR ${ }^{+} \mathrm{CD} 14^{-} \mathrm{CD} 11 \mathrm{c}^{+}$) and $\mathrm{pDCs}$ (HLA-DR ${ }^{+}$ $\mathrm{CD} 14^{-} \mathrm{CD} 11 \mathrm{c}^{-} \mathrm{CD} 123^{+}$). Fast homeostatic proliferation was defined as viable CD4 T-cells which fully diluted CFSE and acquired memory phenotype (CD45RA $\left.{ }^{-}\right)$, while slow homeostatic proliferation was defined as viable naïve CD4 T-cells $\left(\mathrm{CD} 45 \mathrm{RA}^{+}\right)$which partially diluted CFSE. Treg subsets were defined as follows: total Treg $\left(\mathrm{CD} 25^{\text {high }}\right.$ Fox$\mathrm{P}^{\text {high }}$ ), resting Treg $\left(\mathrm{CD} 45 \mathrm{RA}^{+} \mathrm{FoxP}^{+}\right)$and activated Treg $\left(\mathrm{CD} 45 \mathrm{RA}^{-} \mathrm{FoxP}^{\text {high }}\right)$. TGF- $\beta$ production by Treg generated in the cell culture was also determined. Flow cytometry was performed on a LSR Fortessa (BD, USA). Analysis was performed using FlowJo version 9.2 (Tree Star) and data is expressed as mean values and standard deviation $(\sigma)$ of the frequencies and as MFI (Mean Fluorescence Intensity). Graphs were generated using Prism version 5.0 (Graphomeostatic proliferationad Software, USA).

\section{Results}

\section{Effects of homeostatic stimuli on cellular viability and proliferation of human naive CD4 T-cells}

We first explored the effects of each stimulus on cellular viability and proliferation over time. For this purpose, we first tried each individual stimulus separately (aAPC or rIL7). When naive CD4 T-cells were only stimulated with aAPC (1/1 aAPC/Naive ratio), we found that cellular proliferation at day 5 was negligible, though at days 10 and 15 we observed the occurrence of fast homeostatic proliferation (Fig. 3a left panel) and generation of memory cells $\left(\mathrm{CD} 45 \mathrm{RA}^{-}\right)$(Fig. 3a right panel). On the other hand, when naive CD4 T-cells were stimulated only with rIL7 (10 ng/ $\mathrm{ml}$ ), we did not see proliferation at day10 nor day 15 of culture (Fig. 3b left panel); however, it was observed at a 
a)

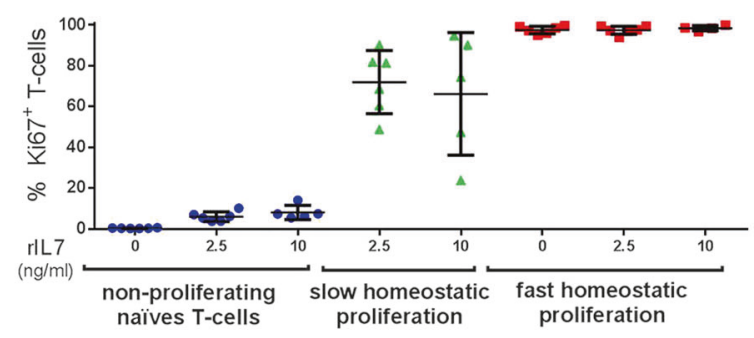

c)

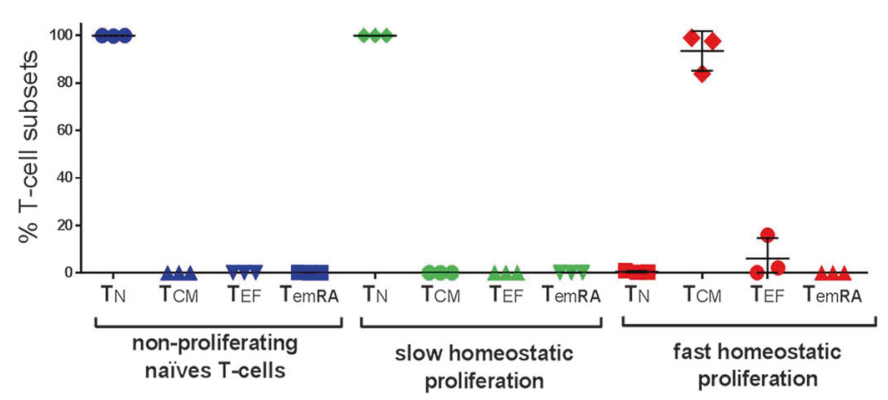

e)

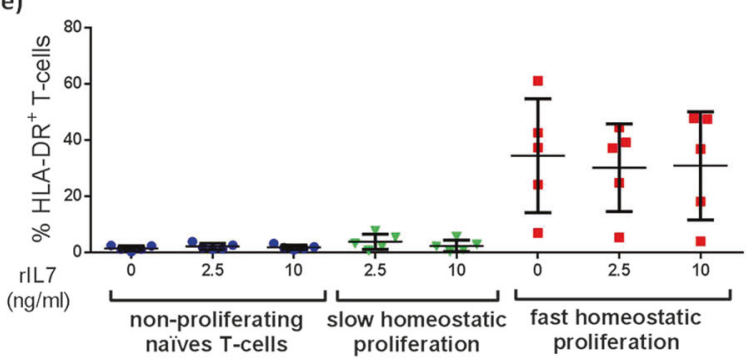

Fig. 5 CD4 T-cell subsets generation and upregulation of cellular markers during homeostatic proliferation. a) Ki67 upregulation during homeostatic proliferation; b) BCL2 upregulation during homeostatic proliferation; c) CD4 T-cell subsets generation during homeostatic proliferation $(2.5 \mathrm{ng} / \mathrm{ml} \mathrm{rIL} 7)$. Similar results were observed with other rIL7 concentrations (data not shown); d) $\beta 7$-integrin upregulation during

very low level after 22 days of culture (Fig. 3b left-right panels). Eventually, a third condition including both stimuli was tested. Under these conditions, naive CD4 T-cells underwent fast and slow homeostatic proliferation at the 10th and 15th days of culture (Fig. 3c left panel), generating both memory and naive T-cells (Fig. 3c right panel). Interestingly, fast homeostatic proliferation did not come earlier when rIL7 was added together with aAPC. In contrast, slow homeostatic proliferation was detected significantly sooner when naive CD4 T-cells were simultaneously stimulated with both stimuli.

\section{Effect of aAPC/Naive ratio and rIL7 concentration on both types of homeostatic proliferation}

First, we performed the culture using different aAPC/Naive ratios $(1 / 1,1 / 10,1 / 20$, and 1/30 ratios). We found that fast homeostatic proliferation decreased at a ratio of 1:10 in the

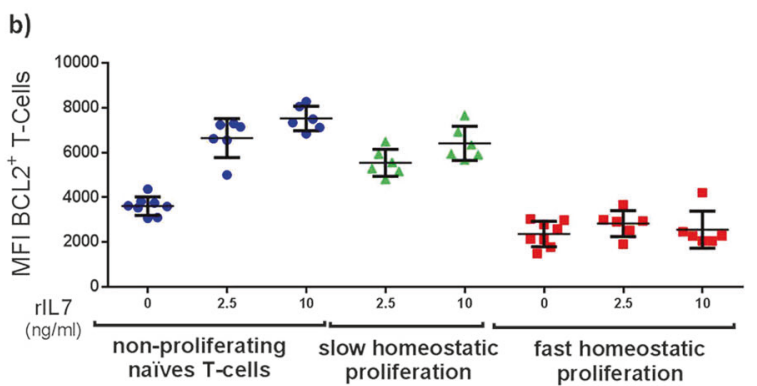

d)
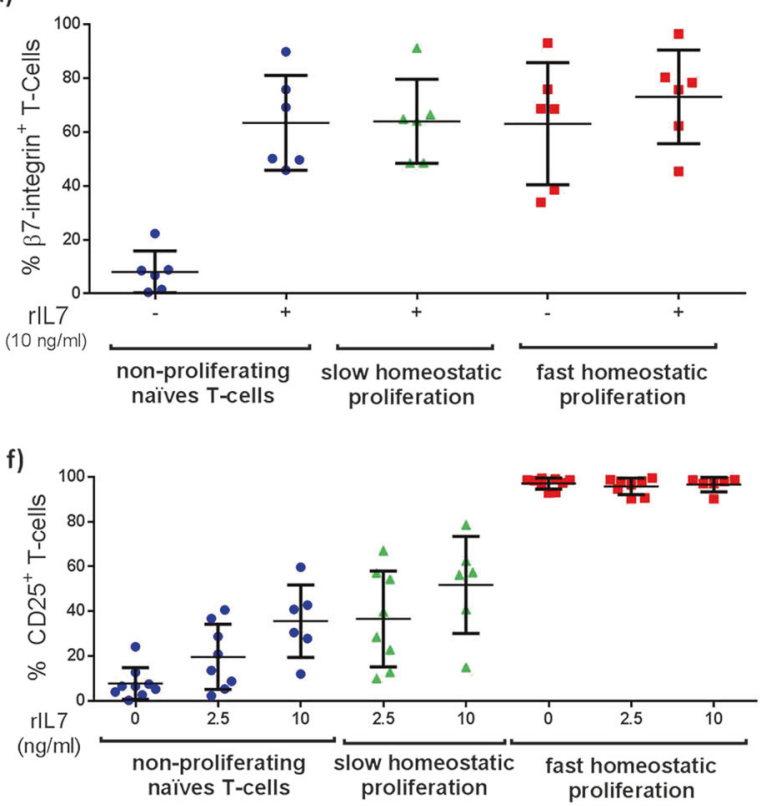

homeostatic proliferation; e) HLA-DR upregulation during homeostatic proliferation; f) CD25 upregulation during homeostatic proliferation. Data were obtained at $10^{\text {th }}$ day of a $1 / 1$ ratio aAPC/Naive culture and are represented as median value and standard deviation (SD). Fast homeostatic proliferation, slow homeostatic proliferation and non-proliferating T-cells are highlighted using red, green and blue dots, respectively

absence of IL-7, but at a ratio of 1:20 in the presence of the cytokine (Fig. 4a), denoting that when aAPC/Naive ratio decreased, the presence of rIL7 enhanced fast homeostatic proliferation.

In order to study the effect of rIL7 concentration on homeostatic proliferation, we used a range of rIL7 (0-10 ng/ $\mathrm{ml})$ in our culture (1/1 aAPC/Naive ratio). We observed that low rIL7 concentrations were sufficient to induce slow homeostatic proliferation (Fig. 4b), but small differences were found between the various rIL7 concentrations. Similarly, no effect of different rIL7 concentrations was observed over fast homeostatic proliferation with $1 / 1$ aAPC/Naive ratio.

\section{Fast homeostatic proliferation of human naive CD4 T-cells mainly generates central memory T-cells}

To explore the usefulness of our in vitro system, we performed immunophenotyping of cells undergoing 
a)

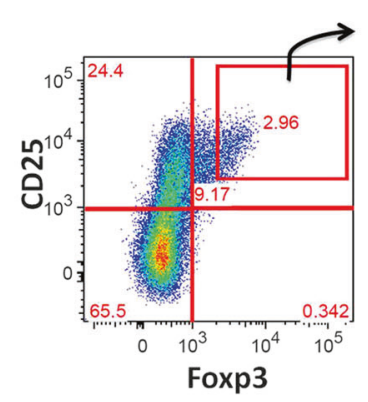

total Treg

CD25 high Foxp $3^{\text {high }}$

b)
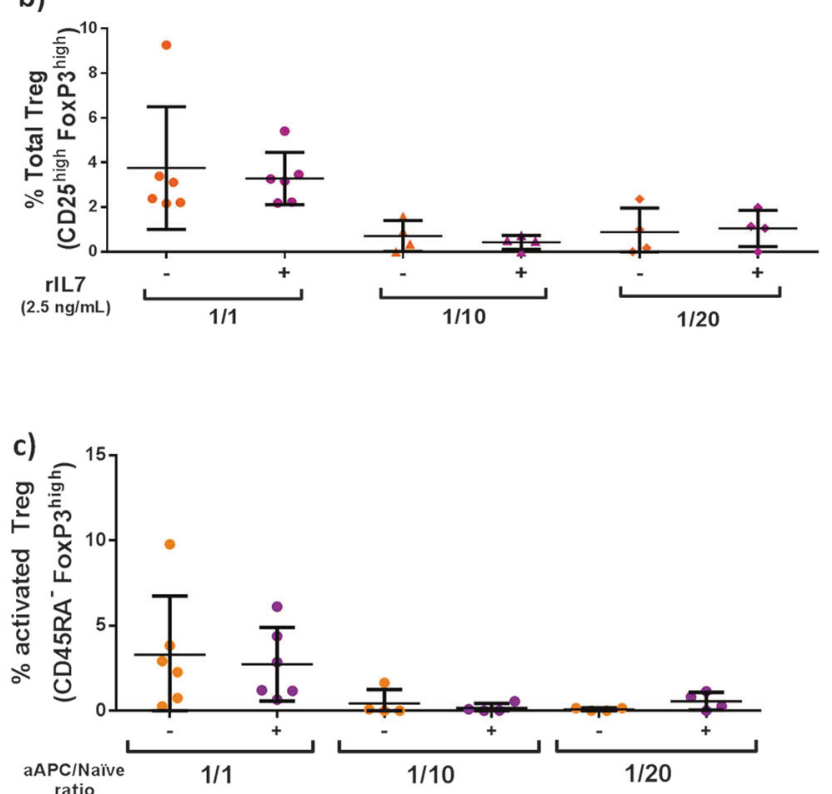

d)

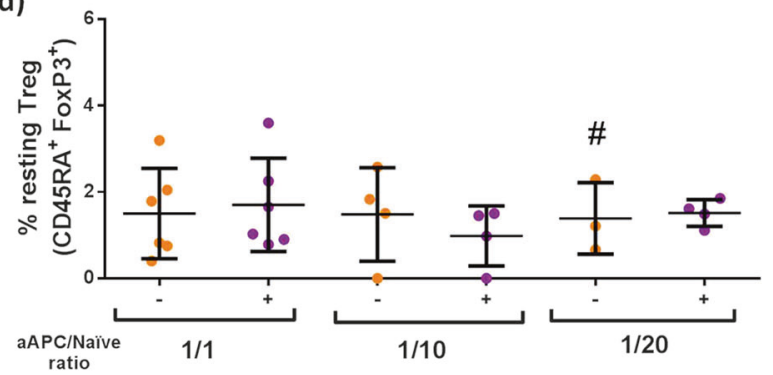

Fig. 6 Treg generation during human homeostatic proliferation. a Representative gating plot of generated total Treg $\left(\mathrm{CD} 25^{\text {high }}\right.$ Fox$\left.\mathrm{P}^{\text {high }}\right)$, resting and activated Treg $\left(\mathrm{CD} 45 \mathrm{RA}^{+} \mathrm{FoxP}^{+}\right.$and $\mathrm{CD}^{+} 5 \mathrm{RA}^{-}$ FoxP $3^{\text {high }}$, respectively). Plot are representative of at least 6 independent experiments (a different donor each experiment). b Total Treg $\left(\mathrm{CD} 25^{\text {high }} \mathrm{FoxP} 3^{\text {high }}\right)$ generation with different aAPC/Naive ratios and different concentrations of IL-7 (1:1 aAPC/Naive ratio); $\mathbf{c}$ activated Treg (CD45RA-FoxP3 ${ }^{\text {high }}$ ) generation with different aAPC/Naive ratios and different concentrations of IL-7 (1:1 aAPC/Naive ratio); d

homeostatic proliferation. As expected, cells that diluted CFSE upregulated the cellular-cycling marker Ki67 while cells that did not diluted CFSE barely expressed this marker (Fig. 5a). The upregulation of Ki67 was higher in fast
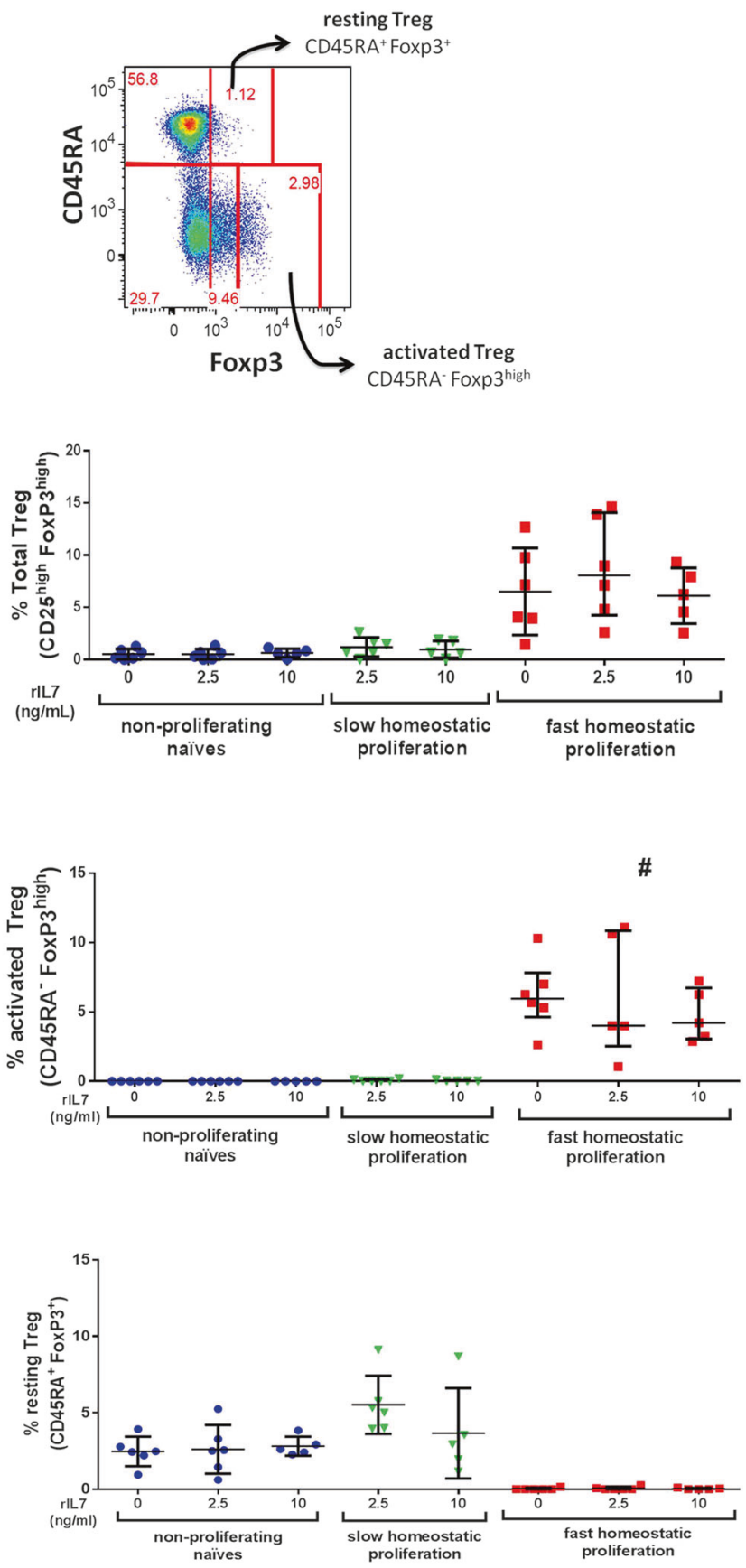

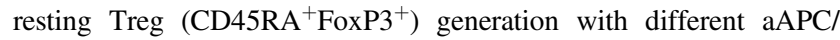
Naive ratios and different concentrations of IL-7 (1:1 aAPC/Naive ratio). Data were obtained at 10th day of culture and are represented as median value and standard deviation (SD). \# Outlier value has been excluded. Culture conditions with and without rIL7 are highlighted in purple and orange dots, whereas non-proliferating naive T-cells, slow proliferated T-cells and fast proliferated T-cells are highlighted in blue, green and red dots, respectively

homeostatic proliferation than in slow homeostatic proliferation in all culture conditions. Moreover, Ki67 expression was slightly increased in non-proliferating cells in the presence of rIL7. Likewise, we observed a rIL7 dose- 

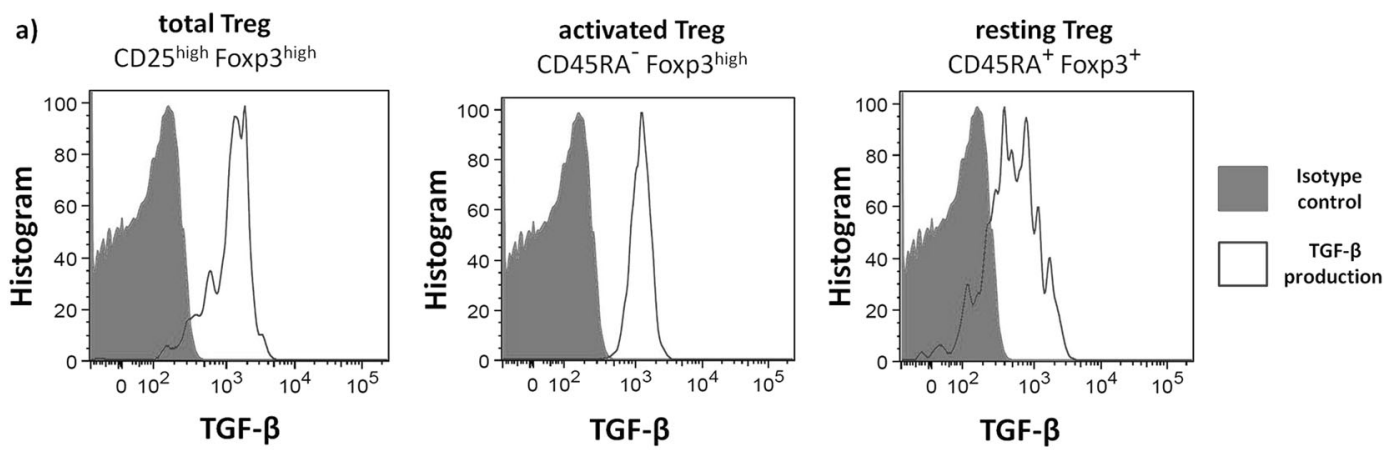

b)

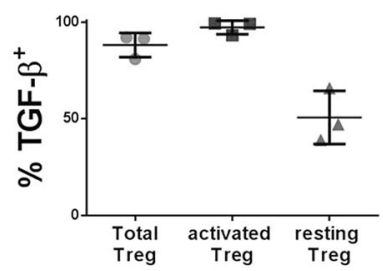

Fig. 7 Tregs generated during homeostatic proliferation are able to produce TGF $\beta$. a representative histogram of TGF- $\beta$ production by different Treg subsets. Isotype control is shown as a shaded histogram whereas TGF- $\beta$ production is shown as an empty histogram; b TGF- $\beta$ production by resting, activated and total Treg generated by

dependent upregulation of the anti-apoptotic molecule $\mathrm{Bcl} 2$ in non-proliferating naive CD4 T-cells and cells that underwent slow homeostatic proliferation (Fig. 5b), though this effect seemed to be absent in cells undergoing fast homeostatic proliferation.

Next, we explored the maturational profile of cells undergoing homeostatic proliferation in our in vitro system. Cells undergoing slow homeostatic proliferation maintained their naive phenotype $\left(\mathrm{CD} 45 \mathrm{RA}^{+} \mathrm{CD} 27^{+}\right)$, whereas cells undergoing fast homeostatic proliferation acquired mostly central memory phenotype $\left(\mathrm{CD} 45 \mathrm{RA}^{-} \mathrm{CD} 27^{+} \mathrm{CCR}^{+}\right.$) (Fig. 5c).

\section{Homing and activation-related markers are up-regulated during homeostatic proliferation process}

On the one hand, we found a strong upregulation of $\beta 7$ integrin in cells undergoing fast homeostatic proliferation in a rIL7-independent manner (Fig. 5d). Otherwise, cells that underwent slow homeostatic proliferation as well as nonproliferating cells also upregulated $\beta 7$-integrin but only in the presence of rIL7 (Fig. 5d). Additionally, we observed that cells undergoing fast homeostatic proliferation strongly upregulated HLA-DR, whereas no effect was observed in non-proliferating naive T-cells and a negligible upregulation seemed to occur in cells undergoing slow homeostatic proliferation (Fig. 5e). This effect was independent of the rIL7 concentration. Similarly, cells undergoing fast homeostatic proliferation strongly upregulated CD25 in a

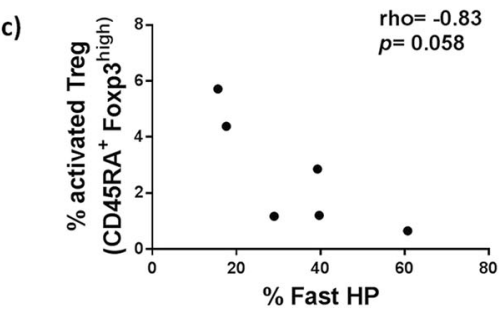

homeostatic proliferation; c negative correlation between the frequencies of generated activated Tregs and the size of fast homeostatic proliferation. Data were obtained at 10th day of culture and are represented as median value and standard deviation (SD)

rIL7-independent manner (Fig. 5f). However, a rIL7dependent upregulation of CD25 in non-proliferating cells and cells undergoing slow homeostatic proliferation was observed (Fig. 5f).

\section{Different types of regulatory T-cells are generated during the human homeostatic proliferation process}

We seeded Treg-depleted naive CD4 T-cells, and after 10 and 15 days of culture, we observed the generation of Treg cells (CD25 $5^{\text {high }}$ Foxp3 $3^{\text {high }}$ ) (Fig. 6a left). Next, we characterized the generation of such Treg in different aAPC/ Naive ratios and rIL7 concentrations. We found that Treg $\left(\mathrm{CD} 25^{\text {high }}\right.$ Foxp $\left.3{ }^{\text {high }}\right)$ generation during homeostatic proliferation was highly hampered when the aAPC/Naive ratio was decreased (Fig. 6b left) denoting that such process is highly dependent on the contact with aAPC. Differently, no effect of the rIL7 exposure on Treg generation was observed (Fig. 6b right). Moreover, we found that Treg $\left(\mathrm{CD} 25^{\text {high }}\right.$ Foxp $\left.3^{\text {high }}\right)$ were mainly generated in the cellular fraction that underwent fast homeostatic proliferation (Fig. 6b right). In addition, we observed the generation of different subsets of Tregs, as resting Treg $\left(\mathrm{CD} 45 \mathrm{RA}^{+}\right.$Foxp3 $\left.{ }^{+}\right)$and activated Treg (CD45RA ${ }^{-}$Foxp $\left.3^{\text {high }}\right)$ during homeostatic proliferation (Fig. 6a right). Similar results were found regarding aAPC/Naive ratio and rIL7 exposure impact on the generation of these subsets (Fig. 6c, d), excepting for resting Treg which seems not to be affected by the aAPC/Naive ratio reduction. Finally, in order to 
explore whether such generated Treg could be functionally suppressive, we analyzed the production of transforming growth factor (TGF- $\beta$ ) by these cells. Interestingly, all generated Treg subsets were able to produce such cytokine (Fig. 7a), but activated Treg produced higher levels than resting Treg (Fig. 7b). Furthermore, we observed a negative trend between the size of fast homeostatic proliferation and the frequency of activated Treg (Fig. 7c), but not with resting or total Treg (rho $=-0.371, p=0.5$; rho $=-0.657, p=0.2$; respectively).

\section{Discussion}

We have designed and characterized an in vitro experimental procedure useful for the study of the homeostatic proliferation process of human naive CD4 T-cells. Our in vitro model is based on a cell culture of autologous human leukocytes that allows simultaneously exploring fast and slow homeostatic proliferation in response to homeostatic stimuli.

It is well-known that human peripheral lymphocyte pools are maintained at constant levels througout life [1, 2]. However, the decline of lymphocyte numbers is a feature of several human disorders in which the homeostatic proliferation process is of crucial importance [11]. In order to study such process many in vitro and in vivo models have been developed. Nevertheless, these different models have often reported different results depending on their methodology. For instance, Cimbro et al, studied the effects of IL7-exposure on the T-cell expression of $\alpha 4 \beta 7$-integrin using different models: wild-type and humanized mice models, and samples of HIV-infected subjects from a clinical trial with IL7-treatment [12]. Interestingly, they observed that naive T-cells from humanized mice model and from HIV-infected subjects treated with IL7 strongly upregulated the $\alpha 4 \beta 7$-integrin. However, the T-cells from wild-type mice model did not increase their $\alpha 4 \beta 7$-integrin levels after IL7-treatment. Similarly, other studies about IL7-exposure in different animal models as rhesus macaques showed that IL7-treatment increased the expression of both activation-markers HLA-DR and CD25 on naive Tcells [13], however Cimbro et al, conversely found that only CD25 was modestly upregulated on IL7-treated naive Tcells from HIV-infected subjects. These and others discrepancies are probably due to the use of different animal models, and also to the use of strong stimuli, like anti-CD3/ CD28 beads. Trying to address this issue, we have generated an in vitro model that allows the simultaneous study of both types of homeostatic proliferation. The employment of more natural homeostatic stimuli like autologous APC, rather than the use of stimuli like in vitro generated APC or antiCD3/CD28 beads, allows exploring into the model the natural inter-individual variability in the antigen-presentation, which has been reported to notably impact the homeostatic proliferation process [7]. This is particularly relevant considering that different lymphopenia-related disorders could be associated with a different distribution of APCs and different phenotypic profiles. Thus, different donor-associated characteristics of aAPC could determinate both, the extension of homeostatic proliferation and the phenotypic and functional properties of cells that had proliferated. Along the same line, the use of the autologous fraction of naive CD4 T-cells constitutes another advantage of our design, since this fraction also includes CD4 recent thymic emigrants (RTE) (CD45RO- selected cells), which are largely dependent of age of donors and could also undergo homeostatic proliferation, though generally slowly, since they are highly unresponsive to TCR signals but show high expression of CD127 (IL-7R) [14]. These characteristics could make our approach a useful tool to explore specific features of human homeostatic proliferation process in different human lymphopenia-related disorders as HIV-infection, aging, chemotherapy and pre-transplantation drug-treatment [15-17].

Using our model, we confirmed that both rIL7 exposure and aAPC are survival signals that ultimately lead to homeostatic proliferation of human naive CD4 T-cells. Moreover, we found that, while fast and slow homeostatic proliferation were respectively antigen- and rIL7-driven, both homeostatic stimuli can synergize, enhancing both types of homeostatic proliferation. Finally, we observed that both fast and slow homeostatic proliferation are generated at the same time in our culture, though fast homeostatic proliferation showed a more exponential proliferation. Importantly, our results confirm previous observations regarding the homeostatic stimuli triggering such process $[8,18,19]$.

The homeostatic proliferation process has been associated with cellular differentiation. We have observed in our model that fast homeostatic proliferation ultimately generates mostly central and transitional memories in all studied culture conditions. However, most in vivo studies using animal models have described that fast homeostatic proliferation mainly generates effector memory cells [20, 21]. It is reasonable to suppose that humans and other animals could have differences in the cellular differentiation process related to homeostatic proliferation. Similarly, using our in vitro model we analyzed the expression of activation markers (HLA-DR/CD25) in both types of homeostatic proliferation. We observed that fast homeostatic proliferation upregulated both activation markers (CD25/HLA-DR), indicating that fast homeostatic proliferation can generate activated memory-cells which could be involved in the level of systemic activation reported in some human lymphopenia-related diseases as HIV-infection [22]. On the other hand, we also observed a milder upregulation of CD25 but not of HLA-DR in T-cells that underwent slow homeostatic proliferation, suggesting that slow homeostatic proliferation generates cells with a lesser activated 
phenotype. Interestingly, whereas no effect of IL7 administration was found in the HLA-DR modulation during homeostatic proliferation, an IL7 dose-dependence effect was observed in CD25 upregulation in the non-proliferating naive T-cells and in slow homeostatic proliferation, though not in fast homeostatic proliferation.

Under physiologic conditions, $\beta 7$-integrin mediates the T-cell homing to mucosal surfaces; this process is of pivotal importance in the maintenance of immune homeostasis [23]. The disturbance of such balance has been associated with diverse pathologies in humans and animal models [24, 25]. In murine models, it has been reported that homeostatic proliferation can generate homing-imprinted T-cells [21]. Similarly, it has been reported that human T-cells also upregulates such homing molecules after a IL7-exposure [12], though it has not been explored in the human fast homeostatic proliferation. Using our in vitro model, we have explored this process more deeply, finding that fast homeostatic proliferation also upregulates the expression of $\beta 7$-integrin but in a IL7-independent manner, being in accordance with other in vivo animal models [21]. In contrast, we also found an upregulation of $\beta 7$-integrin in an IL7-dependent manner in the non-proliferated naive T-cells and in slow-proliferated T-cells. Collectively, our results indicate that the main target of most homeostatically proliferated human CD4 T-cells are the mucosal surfaces, probably the gut lymphoid-associated tissue (GALT), denoting the importance of immune reconstitution of such structures to immune homeostasis.

The reconstitution of regulatory T-cell pool is also crucial for the immune homeostasis after immunodepletion $[26,27]$. The homeostatic proliferation process was shown to be an intrinsic source of these suppressive T-cells during the immune reconstitution in animal models [28]. Accordingly, we have observed a generation of Treg $\left(\mathrm{CD} 25^{\text {high- }}\right.$ FoxP3 ${ }^{\text {high }}$ ) during homeostatic proliferation of human Tcells in our system. Specifically, these Tregs were generated by fast homeostatic proliferation, which is driven by selfand commensal-antigens. It is relevant to note that our system allows exploring the contribution of a particular aAPC fraction on Treg generation, considering that the maturation profile and the expression of tolerogenic enzymes in these cells are determinant in this process [29]. Importantly, we have performed a characterization of such process exploring how IL7 exposure and aAPC/Naive ratio impact on it. Whereas no effect of IL7 exposure was observed, a high dependence on aAPC/Naive ratio was found on Treg generation. Additionally, we also observed the generation of different subsets of Treg, resting $\left(\mathrm{CD} 45 \mathrm{RA}^{+} \mathrm{FoxP}^{+}{ }^{+}\right.$) and activated Treg (CD45RAFox$\left.\mathrm{P} 3^{\text {high }}\right)$. The role of such generated Treg cells during homeostatic proliferation could be the suppression of the excessive cellular proliferation [30], trying to ensure the control of the immune reconstitution process [26]. In fact, homeostatic proliferation-generated Treg cells in our culture were able to produce TGF- $\beta$, and a pivotal role of such cytokine in the control of fast homeostatic proliferation and prevention of autoimmunity has been previously reported [31, 32]. Interestingly, a strong negative trend between the frequency of activated Treg and the size of fast homeostatic proliferation was observed in our culture system. Consistently, in murine models, it has been reported that Treg can regulate the extension of homeostatic proliferation through the specific suppression of fast homeostatic proliferation [30]. Accordingly, others have reported a protective role of Treg over the development of graft-vs.-host disease (GVHD) during immune reconstitution both in animal models and humans [26, 27]. All these observations suggest that Treg, suppressing the excessive proliferation of CD4 T-cells, are crucial for correct immune reconstitution after immunodepletion, preventing autoimmunity disease or even the failure of such T-cell reconstitution [33].

Our in vitro system has also limitations. Homeostatic proliferation process takes place in secondary lymphoid tissues [34], but such a structure is not present into our model. Thus, even though we have observed that T-cells that underwent homeostatic proliferation upregulated homing markers, these cells cannot migrate to their target tissue. However, the specific concentrations of IL7 and ratios with APC in the lymphoid tissue can vary among different subjects and among different scenarios. Thus, this limitation affects not only ours but also most used models. Nevertheless, the in vitro condition of our model confers plasticity to the study of homeostatic proliferation in different degrees of lymphopenia pressure, which can be performed modifying the rIL7 concentration and the ratio aAPC/Naive T-cells. In addition, the use of autologous APC provides the natural inter-individual variability in the antigen presentation of each subject and could also allow exploring potential associations between the composition of the APC fraction and homeostatic proliferation in particular scenarios. Another question is whether the fraction of $\left(\mathrm{CD}_{45 \mathrm{RO}^{-}}\right) \mathrm{CD} 4$ naive T-cells could be contaminated with TEMRA cells, which constitute a negligible fraction in healthy donors, but could accumulate in different pathogenic scenarios (such as infections). Nevertheless, a potential contamination with TEMRA cells would not interfere in our system since these cells: (a) show a replicative senescence phenotype $\left(\mathrm{CD} 28^{-} \mathrm{CD} 57^{+}\right)$, (b) would not loss CD45RA with further cell divisions and (c) show low expression of CD127 (IL-7R). Thus, they could only appear as a new pool of $\mathrm{CFSE}^{-} \mathrm{CD}^{2} 5 \mathrm{RA}^{+}$, which has not been observed in our cultures.

In summary, our in vitro model is able to reproduce simultaneously both types of homeostatic proliferation 
process of human naive CD4 T-cells, as well as to reproduce several in vivo observed phenomena related to such homeostatic proliferation. Hence, our in vitro model can be a useful tool to explore specific features of human homeostatic proliferation process in different human lymphopenia conditions and diseases and could be used as a cell therapy approach.

Acknowledgements This work was supported by grants from the Instituto de Salud Carlos III, Fondo de Investigación Sanitaria (FIS; PI14/01693) (Co-funded by European Regional Development Fund/ European Social Fund) "Investing in your future") and the Junta de Andalucía, Consejería de Economía, Innovación, Ciencia y Empleo (Proyecto de Investigación de Excelencia; CTS2593). The Spanish AIDS Research Network of Excellence supported this study (RIS; RD12/0017/0029 and RD16/0025/0019). Y.M. Pacheco was supported by the Fondo de Investigación Sanitaria through the "Miguel Servet" program (CPII13/00037), and by the Consejería de Salud y Bienestar Social of Junta de Andalucía through the "Nicolás Monardes" program (C-0010/13). We thank $\mathrm{M}^{\mathrm{a}}$ Antonia Abad, Marta de Luna and Cytometry Service of IBiS, especially $\mathrm{M}^{\mathrm{a}}$ José Castro, for their technical assistance. We also thank to Manuel Moyano from Centro Regional de Transfusión Sanguínea de Sevilla-Huelva y Banco de Tejidos (Seville, Spain) for the kind gift of samples.

\section{Compliance with ethical standards}

Conflict of interest The authors declare that they have no conflict of interest.

\section{References}

1. Goldrath AW, Bevan MJ. Selecting and maintaining a diverse Tcell repertoire. Nat Rev Immunol. 1999;402:255-62.

2. Freitas AA, Rocha B. Population biology of lymphocytes: the flight for survival. Annu Rev Immunol. 2000;18:83-111.

3. Sener A, Tang AL, Farber DL, et al. Memory T-cell predominance following T-cell depletional therapy derives from homeostatic expansion of naive T cells. Am J Transplant. 2009;9:2615-23.

4. Hakim FT, Memon SA, Cepeda R, et al. Age-dependent incidence, time course and consequences of thymic renewal in adults. J Clin Invest. 2005;115:930-9.

5. Takada K, Jameson SC. Naive T cell homeostasis: from awareness of space to a sense of place. Nat Rev Immunol. 2009;9:823-32.

6. Surh CD, Sprent J. Homeostasis of naive and memory T cells. Immunity. 2008;29:848-62.

7. Do J, Foucras G, Kamada N, et al. Both exogenous commensal and endogenous self antigens stimulate $\mathrm{T}$ cell proliferation under lymphopenic conditions. Cell Immunol. 2012;272:117-23.

8. Min B, Yamane H, Hu-Li J, et al. Spontaneous and homeostatic proliferation of $\mathrm{CD} 4 \mathrm{~T}$ cells are regulated by different mechanisms. J Immunol. 2005;174:6039-44.

9. Ge Q, Rao VP, Cho BK, et al. Dependence of lymphopeniainduced $\mathrm{T}$ cell proliferation on the abundance of peptide MHC epitopes and strength of their interaction with $\mathrm{T}$ cell receptors. Proc Natl Acad Sci USA. 2001;98:1728-33.

10. Ringhoffer S, Rojewski M, Döhner H, et al. T-cell reconstitution after allogeneic stem cell transplantation: assessment by measurement of the sjTREC / $\beta$ TREC ratio and thymic naive T cells. Haematologica. 2013;98:1600-8.
11. Williams KM, Hakim FT, Gress RE. T cell immune reconstitution following lymphodepletion. Semin Immunol. 2007;19:318-30.

12. Cimbro R, Vassena L, Arthos J, et al. Interleukin-7 induces expression and activation of integrin $\alpha 4 \beta 7$ promoting naive T-cell homing to the intestinal mucosa. Blood. 2012;120: 2610-9.

13. Beq S, Nugeyre MT, Ho T, et al. IL-7 Induces immunological improvement in SIV-infected rhesus macaques under antiviral therapy. J Immunol. 2006;176:914-22.

14. Haines CJ, Giffon TD, Lu LS, et al. Human CD4+T cell recent thymic emigrants are identified by protein tyrosine kinase 7 and have reduced immune function. J Exp Med. 2009; 206:275-85.

15. Chomont N, El-Far M, Ancuta P, et al. HIV reservoir size and persistence are driven by $\mathrm{T}$ cell survival and homeostatic proliferation. Nat Med. 2009;15:893-900.

16. Martinet KZ, Bloquet S, Bourgeois C. Ageing combines CD4 T cell lymphopenia in secondary lymphoid organs and $\mathrm{T}$ cell accumulation in gut associated lymphoid tissue. Immun Ageing. 2014;11:1-13.

17. Jones JL, Thompson SA, Loh P, et al. Human autoimmunity after lymphocyte depletion is caused by homeostatic T-cell proliferation. Proc Natl Acad Sci. 2013;110:20200-5.

18. Pearson C, Silva A, Saini M, et al. IL-7 determines the homeostatic fitness of $\mathrm{T}$ cells by distinct mechanisms at different signalling thresholds in vivo. Eur $\mathrm{J}$ Immunol. 2011;41:3656-66.

19. Hennion-Tscheltzoff O, Leboeuf D, Gauthier SD, et al. TCR triggering modulates the responsiveness and homeostatic proliferation of CD4+thymic emigrants to IL-7 therapy. Blood. 2013;21:4684-93.

20. Booki M, Hidehiro Y, Jane HL, et al. Spontaneous and homeostatic proliferation of $\mathrm{CD} 4 \mathrm{~T}$ cells are regulated by different mechanisms. J Immunol. 2005;174:6039-44.

21. Kawabe T, Sun SL, Fujita T, et al. Homeostatic proliferation of naive $\mathrm{CD} 4+\mathrm{T}$ cells in mesenteric lymph nodes generates guttropic Th17 cells. J Immunol. 2013;190:5788-98.

22. Sousa AE, Carneiro J, Meier-Schellersheim M, et al. CD4 T cell depletion is linked directly to immune activation in the pathogenesis of HIV-1 and HIV-2 but only indirectly to the viral load. J Immunol. 2002;169:3400-6.

23. Gorfu G, Rivera-Nieves J, Ley K. Role of $\beta 7$ integrins in intestinal lymphocyte homing and retention. Curr Mol Med. 2009;9:837-50.

24. Rivera-Nieves J, Olson T, Bamias G, et al. L-selectin, alpha 4 beta 1 , and alpha 4 beta 7 integrins participate in CD4+T cell recruitment to chronically inflamed small intestine. J Immunol. 2005; 174:2343-52.

25. Apostolaki M, Manoloukos M, Roulis M, et al. Role of $\beta 7$ integrin and the chemokine/chemokine receptor pair CCL25/CCR9 in modeled TNF-dependent Crohn's disease. Gastroenterology. 2008;134:2025-35.

26. Di Lanni M, Falzetti F, Carotti A, et al. Tregs prevent GVHD and promote immune reconstitution in HLA-haploidentical transplantation. Blood. 2001;117:3921-9.

27. Nguyen VH, Shashidhar S, Chang DS, et al. The impact of regulatory $\mathrm{T}$ cells on $\mathrm{T}$-cell immunity following hematopoietic cell transplantation. Blood. 2008;111:945-54.

28. Curotto De Lafaille MA, Lino AC, Kutchukhidze N, et al. CD25$\mathrm{T}$ cells generate $\mathrm{CD} 25+$ Foxp3+regulatory $\mathrm{T}$ cells by peripheral expansion. J Immunol. 2004;173:7259-68.

29 Maldonado RA, von Andrian UH. How tolerogenic dendritic cells induce regulatory T cells. Adv Immunol. 2010;108:111-65.

30. Winstead CJ, Fraser JM, Khoruts A. Regulatory CD4+CD25 + Foxp $3+\mathrm{T}$ cells selectively inhibit the spontaneous form of 
lymphopenia-induced proliferation of naive T cells. J Immunol. 2008;180:7305-17.

31. Zhang N, Bevan MJ. TGF-beta signaling to $\mathrm{T}$ cells inhibits autoimmunity during lymphopenia-driven proliferation. Nat Immunol. 2012;13:667-73.

32. Surh CD, Sprent J. TGF- $\beta$ puts the brakes on homeostatic proliferation. Nat Immunol. 2012;13:628-30.
33. Matsuoka K, Kim HT, McDonough S, et al. Altered regulatory T cell homeostasis in patients with CD4+lymphopenia following allogeneic hematopoietic stem cell transplantation. J Clin Invest. 2010;120:1479-93.

34. Reichardt P, Dornbach B, Gunzer M. APC, T cells, and the immune synapse. Curr Top Microbiol Immunol. 2010; 340:229-49. 